RESEARCH ARTICLE

\title{
The Epistemic Value of Music
}

\author{
Marina Bakalova*
}

Received: 16 April 2019 / Revised: 9 September 2019 / Accepted: 15 December 2019

Abstract: Assuming that music can be expressive, I try to answer the question whether musical expressiveness has epistemic value. The article has six parts. In the first part, I provide examples of what music can express. I suggest that it can express inner states with phenomenal character. In the second part, I build up an argument in favor of the claim that, granted its expressiveness, music can convey conceptual content which is not verbal, and which cannot be expressed verbally. This conclusion is limited to concepts like lyrical, nostalgic, melancholy, joyful, distressful etc. In the third part, I explain what musical expressive content is, in contrast and by analogy to, propositional content. In the fourth part, I apply Mitchell Green's multispace model of artistic expression to music. I argue that Green's theory of expression provides a powerful explanation of how a musical sequence can express states with phenomenal character. In the fifth part, I use that model to define adequacy conditions for musical expressive ascriptions. In the last part, I attempt to explain musical knowledge by combining Green's multi-space model with Sosa-style virtue epistemology.

Keywords: Cross-modal congruence; knowledge as success from ability; musical expressiveness; phenomenal concepts.

* Bulgarian Academy of Sciences

(D) https://orcid.org/0000-0002-2847-1037

Institute for Philosophy and Sociology, Bulgarian Academy of Sciences, 13A Moskovska Str., Sofia 1000, Bulgaria

$\bowtie$ marina.bakalova@gmail.com

() The Author. Journal compilation (C) The Editorial Board, Organon F.

This article is distributed under the terms of the Creative Commons Attribution-NonCommercial 4.0 International Public License (CC BY-NC 4.0). 


\section{Introduction}

Does listening to music deliver valuable knowledge to the listener: knowledge that is not trivial, knowledge that is causally efficient, and knowledge that one cannot easily gain otherwise? To many this question would sound unrealistically demanding apropos the cognitive potential of music. There is a simple reason why. Normally, I cannot let you know that mice are mammals or that World War I started on July 28, 1914 by playing you a piece of music. This holds for a long list of propositions about the external world that we paradigmatically take to constitute our knowledge.

In this article, I will try to show that music has epistemic value beyond that straightforward consideration, and that it gives us non-trivial knowledge which is causally efficient, and which we cannot easily gain otherwise. I claim that, granted its expressive potential, music gives us knowledge of the phenomenal character of real or imaginary inner states and episodes. In particular, it does so by displaying typical qualitative characteristics of these states and episodes in sound sequences. How can a sound sequence display phenomenal characteristics? The obvious answer is: by expressing them. When I use the term "expressing" I will mean expressing a state as opposed to expressing a particular person's state.

The presence of phenomenal characteristics, of course, essentially depends on our capability of grasping them. I shall argue, together with Mitchell Green (2007, 178-182), that we are capable of creating and grasping artistic expressions due to systematic congruencies between certain expressive stimuli and certain mental states. Such congruencies are due to a general cognitive phenomenon, known as cross-modal (or inter-modal) congruence (to be explained in Section 4). Cross-modal congruence is experimentally proven by Lawrence Marks (1978, 1982, 1987, 1995). My task in this paper is, first of all, to show that the phenomenon of cross-modal congruence is enough to explain musical expression. Because of that, I argue, Green's original theory of artistic expression stands on its own right, and does not need to be backed by the contour and convention theory. ${ }^{1}$ Then I

1 The contour and convention theory presented in (Kivy 1989) and (Kivy 2002) states that music is expressive as a result of a structural analogy with human behavior or, when this is not the case, it is expressive by convention. 
claim that music can supply some of our concepts with conceptual content which, in long term, enhances self-knowledge and enables empathy.

Let me start with few preliminary remarks. I take it for granted that music can be expressive. I will try to give an account of what an average, even unarmed listener can get, epistemically speaking, from listening to music. In order to make things simpler, I will reduce my analysis to two main components: an attentive listener and a piece of expressive music. I will not touch upon other related topics. First, I will not mess with knowledge resulting from the ability to play an instrument or to understand scores. Our listener does not need to have a musical expertise. Secondly, our analysis is independent of three other, often taken as important, factors when knowledge is associated to music: listener's acquaintance with the cultural context of the musical work, her ability to grasp composer's or performer's intentions, and her actually feeling the expressed emotion as opposed to just hearing the expression. These three aspects would certainly enhance listener's epistemic grasp of the expression, but are not necessary for it.

Relatedly, the statement that a particular piece of music expresses something can mean two things. First, it can mean that it expresses something that a composer or a performer intended it to express. Secondly, it can mean that music itself displays emotions. Being expressive of something in this second sense is not strictly tied to anybody intending it to be so expressive. For instance, a piece of music can express an attitude inadvertently. ${ }^{2}$ As I have already mentioned, I will use the verb "express" in the second sense, independently of the composer's intention. Consequentially, I take it that a naïve listener can gain knowledge of the qualitative characteristics of a state simply because these characteristics are present in a piece of music. Thus, I take the following simple condition as basic for my further analysis: if a piece of music is de facto expressive of $x$ one can gain knowledge of $x$ by listening to that piece.

2 For inadvertent creations see (Zvolensky 2016). 


\section{What music can express}

Before addressing the main issue, let me deliberate upon the question of what music is capable of expressing. Music can express states with phenomenal character. State is "a condition or way of being that exists at a particular time." ${ }^{\prime 3}$ Arguably, music can express any state with phenomenal character. ${ }^{4}$ Since music develops through time, the musically expressed states are usually unified in episodes that can have an overall character of their own. Inner episode is a state which develops through time, or a series of states that flow into each other.

In what follows, I will talk about music expressing emotions, feelings, moods, and sense impressions. What is the difference between them? Emotions are automatic reactions in response to our interpretation of specific triggers. They bear clear relation to whatever elicited them. An emotion is typically elicited by evaluating an event as relevant to a goal. It is positive when the goal is advanced and negative when the goal is impeded (Wilson and Keil eds. 1999, 273-275). Emotions are temporary and considered independent of logical reasoning. However, as shown by Antonio Damasio (1994), they play a crucial role in our decision making and rational choice. Feelings can be characterized as emotions processed by thinking and are usually longer-lasting than emotions. They involve awareness of an emotion and awareness of the environment. Moods have similar basis to emotions but lasts longer. Whereas emotion tends to change the course of action, mood tends to resist disruption (Wilson and Keil eds. 1999, 273-275). Next, sense impressions involve awareness due to stimulation of sense organs. The awareness is turned into and memorized as a bodily feeling associated to the presence of these stimulations. Finally, an expressive piece of music is supposed to evoke something in the listener. "To evoke" means to make someone remember or recognize something, i.e. the qualitative character of a state in a musical fragment. Hearing a state in a musical fragment, as I argue further, is enough for recognizing that state. Feeling the state (in the

3 Cambridge dictionary: https://dictionary.cambridge.org/dictionary/english/state.

4 States can be mental or physiological. Mental state is a psychological state as opposed to physiological state such as the state of being pregnant or the state of being thirsty. Most often music expresses mental states.

Organon F 28 (2) 2021: 303-325 
sense of emotional contagion) as opposed to just hearing it is a way of listening to music with greater depth and understanding. Yet, it is not necessary for one's cognitive grasp of the expression.

Music is most often taken to express emotions. An outstanding example of that is the 3rd part of Bartok's Concert for Orchestra, "Elegia" expressing a rich palette of grimness and emotional distress, going in many directions typical of that state. ${ }^{5}$ In contrast to that, the end of the third part of Tchaikovsky's Sixth Symphony, "Pathetic" is massively life-approving, and joyful. Most often music expresses emotional episodes where one emotion is predominant but it is interwoven with a rich palette of other emotions.

Besides emotions music can express also sensations and it can deliver conceptual meaning, or so I would like to argue. Here are a few examples.

The first movement of Beethoven's Six "Pastoral" Symphony starts with an indication on the score by the composer "Awakening of cheerful feelings on arrival at the countryside" and indeed it sounds like being in the middle of the nature enjoying its sights. In the 2nd movement, "Scene by the brook", we can recognize the typical impressions of being around a brook. Not to speak about the 4th movement, "Thunder, Storm", where the threatening impressions of an arriving storm and thunders are ingeniously recreated by the great composer.

Next, music can express concepts or categories like elegance, lyricism, drama, nostalgia, and melancholy in a way that is illuminating in regard to obtaining (a better) understanding of these concepts. More precisely, it can express conceptual content in a non-verbal way. Mozart's Piano Sonata No. 15 (Facile), for instance, is a quite uncontaminated illustration of elegance. Played to a child it could be the child's first encounter with the conceptual meaning of elegance - a concept that is in any case learned ostensively. That

5 The statements that I make about the examples given in this section are based on my personal introspection during listening to these pieces. They were also consulted with professor of conducting and doctor honoris causa of Bulgarian National Conservatory Ivan Bakalov to whom I am very grateful. During a presentation at the Philosophy Department of the University of Liege, Belgium, I played some of these pieces to the audience, and they agreed with the general characterizations provided here. 
music will automatically supply the child's concept of elegance-to-be-mastered with reference to particular qualitative characteristics.

Here are a few other examples of how music can deliver conceptual content. Some musical pieces express concepts by previously established stereotypes. For instance, Schumann's Kinderszenen Pieces, Mendelssohn's Lieder ohne Worte or Chopin's Nocturnes are stereotypical examples of lyricism. They are conventionally described as examples of "lyricism" (e.g. in musical lexica). This does not mean, however, that they express lyricism by convention. Rather, they possess typical features which make them lyrical, and which are experienced as lyrical in a motivated manner. ${ }^{6}$ Again, we can explain to someone what lyrical means by playing any of these works precisely because they embody typical qualities of the lyrical experience. The same holds for other concepts like "nostalgia" and "melancholy". Melancholy music can give us an idea of what melancholy is. Imagine an exercise in which you and I have to find typical musical expressions of nostalgia and melancholy that we agree upon. Such exercise would likely be illuminating for purposes of distinguishing between these two concepts, and gaining deeper understanding of each of them.

Other pieces of music can evoke conceptual content in lack of corresponding stereotypes. For example, Dan Hartman's album New Green Clear Blue is supposed to be a journey in the subconscious. In Hartman's own words:

The basis of this album was to use tones and shades in certain patterns so the door to a listener's subconscious would be opened...There's nothing placed in the music to tell you things. It's merely my trying to tap the subconscious feelings of people who listen to it...I was unlocking my own subconscious. And the first two or three pieces I listened to I felt were planets away from fulfilling my concept. Little by little it began to flow... I sat at the keyboard and created some sounds that seemed interesting. When I listened back, I was amazed it came out completely as one piece.... I played it to my neighbors. Some said it put them in a state where they felt very intimate with themselves. (Campbell 1989, 22)

6 I am grateful to anonymous reviewer for helping me to clarify this idea. 
In short, Hartman's album enabled the listeners to explore their subconscious without a previously settled stereotype. At first, the music he wrote did not correspond to his concept, but then it came out surprisingly as he wanted it because he managed to recreate in sound the phenomenal properties that he felt were right.

Our examples are based on both absolute and program music. ${ }^{7}$ Absolute music refers to purely abstract organization of sounds - to those musical works that contain no titles or words, such as Mozart's Piano concerto No. 21. Program music usually refers to songs, to music complemented with words. When philosophers discuss musical expression they prefer to limit their talk to absolute music. But program music has its own typically musical way of expression. Titles or words of a musical work can trigger one's perceptual imagination to take a certain path; yet music, on its own, does a lot, epistemically speaking, to supply these words with phenomenal content. For example, the title of Hartman's album "New Green Clear Blue" could enable one to experience a blue color as having the characteristics of a new green: freshness, serenity etc. by listening to that music (not just by digesting the verbal meaning). In other words, a musical title is just too schematic and uninformative without the proper musical part. It cannot be considered as entirely determining the musical meaning. Instead, it is just a trigger for listening in a certain way. Hence, program music on its own can convey adequate, clear, and rich information about some of the aspects of our states that we cannot so informatively talk about.

In sum, some words of our languages refer to our states: lyrical, cool, dramatic, stressful, etc. Understanding the full-fledged meaning of these words entails having been in touch with certain phenomenology. Generally speaking, that phenomenology is more efficiently communicated with music than with words. Music enables a first-hand experience of the phenomenology of our states, and thus it contributes to our conceptual knowledge. By doing so, it can serve as fuller-fledged answer to questions like "What does melancholy mean?" than a verbal definition: "a feeling of pensive sadness, typically with no obvious cause". It adds flesh and bones to the verbal meaning.

7 Even though some of the compositions we have been discussing have titles, I have been focusing on what music can convey independently of these titles, as pure abstract organization of sounds. 


\section{The master argument}

Musical examples given in the previous section are meant to support my main argument together with another important premise. Here is the premise. It seems to me uncontroversial that, as far as concepts about inner experiences are concerned, experiences themselves supply us with richer conceptual content than the schematic content encoded in the verbal symbols standing for these concepts. If that is true, we can draw a bolder conclusion: possession of conceptual content is possible without the existence of a corresponding verbal symbol. ${ }^{8}$ Here is an illustration. The phrase "sexual harassment" was introduced in USA in a 1973 report about discrimination called Saturn's Rings by Mary Rowe (Kamberi and Gollopeni 2015). For sure many people had experienced sexual harassment before the phrase was introduced in English language. We can plausibly assume that, since they were acquainted with the phenomenon first-hand, they possessed raw conceptual content related to the verbal label introduced later. In other words, since they knew what it feels to be sexually harassed, they knew what sexual harassment means better than people who had never experienced it. Based on this example we can conclude that possession of conceptual content is possible without the existence of corresponding word or phrase in a language standing for the concept in question. ${ }^{9}$ This statement is crucial for my argument.

Here is the argument itself:

1. We possess concepts of inner experiences, the content of which relates to how these experiences feel like. Examples of such concepts are: lyrical, nostalgic, melancholy, joyful, distressful etc. (assumption)

2. We can possess conceptual content related to such concepts without the existence of corresponding verbal symbols. (from our example of "sexual harassment")

8 I admit that this step of the argument is bold given the debate over the representational nature of the mind during the last sixty years, provoked by the Language of Thought Hypothesis. For an updated version of the hypothesis see (Fodor 2008). However, I think that the statement is justified in the context of my argument.

$9 \quad$ I am grateful to Zsofia Zvolensky for suggesting me to use this example. 
Therefore,

3. A verbal phrase does not necessarily exhaust the conceptual content it stands for. (from 1, 2)

Therefore,

4. In some cases, it is impossible to exhaustively communicate a concept just by using the corresponding verbal phrase. (from 1, 2, 3)

5. Music can convey to the listener conceptual content that words cannot. (from 4 and the musical examples)

6. By listening to music the listener can find in herself emotions or phenomenal experiences, more generally, which she has never experienced before. (from the example of Dan Hartman's album New Green Clear Blue)

This argument clearly approves of an unpopular position, namely that phenomenal experiences have cognitive value which is worth epistemological attention. Accordingly, the putative knowledge that we gain through music is valuable. I think that phenomenology of our senses matters cognitively for at least two reasons. First, without it, we would miss conceptual content that determines our everyday communication. Secondly, how a state feels can have significant causal consequences for our actions. For instance, there are implicit states that we cannot verbally articulate or introspect. Since we cannot introspect them we cannot monitor them either. But they can affect our behaviors. Good examples are unconscious fear and unconscious jealousy. Getting to know the phenomenal character of such states enables one to recognize them within oneself and within others when empathy is needed.

\section{Expressive Content of Music}

One specific difference between musical expression and verbal reports is that listening to music involves first-person perspective of the listener. Music puts the listener in intimate contact with her own states by offering a match for these states. The possibility of matching a musical theme with one's own experiential states is crucial for the capacity of music to convey knowledge to an attentive listener. The match is due to musical theme 
having expressive content which corresponds to the phenomenal character of a state.

I will call articulation of phenomenal character "expressive content". I borrow the notion of content from the contemporary discussions of content of perception to stand for something like "the content of a newspaper" as opposed to "the content of a bucket". ${ }^{10}$ In particular, I will use "expressive content" to stand for musical articulation of the expressed states. ${ }^{11}$ Musical expressive content is very different from propositional content. However, I will argue that it has adequacy conditions by analogy to the way in which propositions have truth conditions. Adequacy conditions of musical experience are crucial for the capacity of music to convey knowledge of our inner states.

In the next two sections, I will address the following two questions: how musical expressive content can match phenomenal character of mental episodes and what adequacy conditions of musical articulation are.

\section{The multi-space model of musical expression}

My argument outlined above is inspired by Mitchell Green's book "SelfExpression" (Green 2007). In the last chapter of the book, Green develops a theory of artistic expression which can serve as a basis for analyzing knowledge that we typically gain through art. He points out that the main role of artistic expression is to show how our feelings feel. This is possible, Green $(2007,178-182)$ claims, due to the phenomenon of inter-modal congruence (also known as cross-modal congruence). According to this phenomenon, some sensations within one sensory modality seem to bear more of an affinity to some sensations within another sensory modality than to

10 The distinction is drawn by Susanna Siegel (2016).

11 This notion of "phenomenal content" comes close to what Paul Noordhof (2018) calls "phenomenal content": "Talk of content at this point is not meant to convey some notion of propositional content. It is simply to capture the thought that our mental lives seem made up from various elements which we cite to characterize what it is like to be undergoing them at a certain point in time. Some of these elements may be no more easy to specify than as a feeling of yearning." (Noordhof 2018, 97) 
others. Examples of the phenomenon include: people systematically relating high pitch with bright light and low pitch with gloomy light. The same holds between sensations, moods, emotions, and all states with phenomenal character. For example, the major chord sounds systematically cheerful to us, whereas the minor chord sounds sad. Other examples that Green cites concern people thinking that yellow is more like the sound of a piccolo than it is like the sound of an oboe; that the smell of sulfur is more like rough than it is like smooth; that the taste of lemon is more like the minor chord C-E flat-G than it is like the major chord C-E-G, etc. (Green 2007, 179) The congruence, Green notices, holds in an irreversible way:

(S)ome kinds of inter- as well as intrapersonal inversions do not seem possible. It is difficult, for instance, to see how there could be an interpersonal inversion as between pain and pleasure. This would require that the experience that I feel upon cutting my hand with a knife is like the experience you feel upon stroking velvet. Likewise, we can rule out the possibility that a minor chord sounds sad to me but happy to you. (Green 2007, 184)

Green provides a methodologically insightful explanation of why and how the congruence occurs. He offers a multi-dimensional explanatory model in order to explain the congruence. Green suggests that our sensations, emotions and moods may be described along a number of dimensions, including the following three:

- intense/mild

- pleasant/unpleasant

- dynamic/static.

Green limits his talk to these three basic dimensions for simplicity having in mind that the theory allows for introduction of unlimited number of such dimensions. Hence, he introduces the idea of a three-dimensional space. Green $(2007,179)$ asks us to imagine the above mentioned dimensions as placed in a coordinate system creating a three-space. He further assumes that we perceive phenomenal characteristics as regions in the three-space. There are few possibilities to locate states in that space. First, imagine a joy which stands phenomenally in a particular intersection between the three dimensions (say rather intense, rather pleasant and relatively 
dynamic). It will be represented with one point in the three-space, an intersection between the three parameters. We will call these points "regions". Alternatively, a state might have phenomenal characteristics only along the intense-mild dimension, but not along the other two dimensions. That state will be mapped as a single point on one dimension only. Finally, a state might be two-dimensional, for instance pleasant and mild but neither dynamic nor static - such as the taste of a smooth cream. This state will be mapped with two dots on two regions along the intense-mild dimension and the pleasant-unpleasant dimension.

The idea of the three-space provides a powerful explanation of how a stimulus can express states with phenomenal character. Compare our example of a joy which stands phenomenally in a particular intersection between the three dimensions (intense, pleasant and dynamic) with an auditory experience that occupies the same or very close particular intersection of these three dimensions (i.e. an intense, pleasant and dynamic sequence of sounds). The two experiences feel the same because they are congruent in the three-space. Granted their congruence, that sequence of sounds can express that joy; a listener can hear it as that joy.

To put it more formally, let us distinguish between an expressive stimulus "ES" and an expressed state, "E". We can plausibly assume that when ES overlaps with a region or a set of regions in the three-space which $\mathrm{E}$ occupies, it expresses E. In the case of precise mapping between the regional spaces of $\mathrm{E}$ and $\mathrm{ES}$, ES will be quite informative about the qualitative character of $\mathrm{E}$. If $\mathrm{E}$ is too complex, presumably $\mathrm{ES}$ can give us an idea of how $\mathrm{E}$ feels even if it does not map all the regions of E. Certainly, there is an issue of how much overlapping is enough to make a state recognizable, but we will not deal with it here.

Let us turn back to music. Music is an art which develops through time. So, if we want to use the three-space theory to explain musical expressiveness we will have to assume that musical expression draws a trajectory of expressive stimuli or regional activations in a multidimensional space and in a multidimensional time. Musical trajectory (MT) is the musical counterpart of what I call ES together with its progression in time. Imagine a state $\mathrm{E}$ developing in time from point $\mathrm{A}$ to point $\mathrm{D}$ and activating different regions in the three-space at different moments: $\mathrm{ABC}$ and $\mathrm{D}$. MT expresses 
E by activating the same three dimensional regions as E. Thus MT enables a listener to phenomenally experience a mental episode developing in time. Table 1 below illustrates the idea.

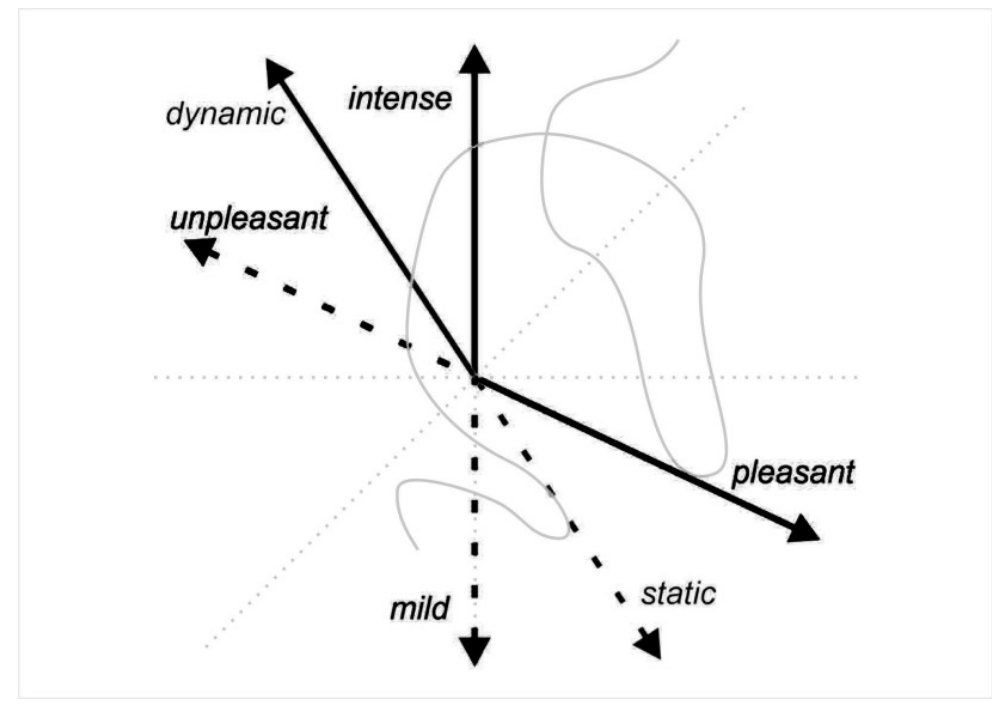

Table 1: Musical trajectory in the three-space

I would like to provide some examples of how the Western musical theory enables composers to "describe" mental attitudes using the three-space. The examples are based on tempo, dynamics and harmony.

Musical tempo allows a composer to place a musical fragment along static-dynamic dimension. The standard expressive tempo forms vary form grave (very, very slow) to largo (very slow) to adagio (quite slow) to andante (a walking pace) to moderato (moderate) to allegro (fast and cheerful) to vivace (lively) to presto (very fast) and finally to prestissimo (fastest). The overall shape of the melody going upward, downward, or remaining static also contributes to that.

Another chapter from the musical theory, dynamics, allows composers to express states along intense-mild dimension ranging from pianissimo to fortissimo. Directions to change dynamics either suddenly or gradually, on the other hand, enable ranging of intensity through time. The standard 
possibilities here are crescendo, decrescendo or diminuendo, sforzando, etc.

What about the pleasant/unpleasant dimension? Music can express different pleasant states such as joy, liberation, triumph, romance etc. On the other hand, it can express sadness, drama, tragedy, horror, anxiety, and other unpleasant states. To start from the unpleasant, there are various ways to suggest an unpleasant state through a piece of music. One way is to accelerate tension, typical of emotions like anxiety, distress, drama, and horror. This can be done by increasing harmonic density, i.e. by harmonic accumulation. Similar effect can be achieved through a denser rhythm as well as by gradually increasing the density of the facture to tutti. We encounter such a way of building tension in "The Death of Tybalt" from Prokofiev's ballet Romeo and Juliet where the timpani beat and the full capacity of the orchestral tutti create a feeling of a strong tension and tragedy. Another example is the $4^{\text {th }}$ part of Beethoven's Pastoral Symphony "Thunder Storm" where use of crescendo and the increase of density of sound and rhythm represent a growing anxiety in the face of upcoming storm. Sadness falls under phenomenally different group of unpleasant states. It is silent and slow. Sadness can be represented by using minor harmony, timbre in the middle to low register, and articulation in legato.

Likewise, there are various ways to express pleasant emotions. Here the choice of a theme is quite important: a well-connected, uninterrupted melody, predominantly in legato, consonant in terms of intervals and harmony creates a feeling of pleasure. For achieving such effect, melody should display certain diversity which helps the development of the phrase. To put it simpler - it should not be boring. Appropriate articulation and diversity of tempo also contribute to expressing pleasant emotions.

These are some basic possibilities. Composer, of course, can use various expressive means simultaneously to place a musical fragment in a single/multidimensional region, and thus to express and articulate phenomenal character of a state developing in time. Western musical system alone is a well-developed and structured palette of such expressive means.

I believe the explanatory potential of the multi-space theory, proposed by Mitch Green, is visible to the reader. One can ask what the nature of this theory is and what its advantages over other theories of musical 
expressiveness are. ${ }^{12}$ I take Green's multi-space theory to be a useful explanatory model of artistic expression. It is used to codify the ways in which we experience affinities among experiences from different sensory modalities. Also, it yields predictions concerning what sorts of congruencies people will experience. For instance, it will predict that people will find yellow more similar to the sound of piccolo than to the sound of oboe; that compositions in minor chord would, more likely, sound sad than joyful to us, etc.

Applied to music, Green's multi-space model has a significant advantage over other theories of musical expressiveness ${ }^{13}$. Unlike any of them, it explains musical expressiveness as property of the music itself. There are two main alternative theories of musical expression: the expressive theory and the arousal theory. The expressive theory explains musical expressiveness in terms of composer's or performer's intentions to express emotion. But it faces the inconvenience of having to explain inadvertent expressions. Green's multi-space theory accounts for that possibility: expressiveness supervenes on the quality of the sound sequence, not on anyone's intention. The arousal theory, on the other hand, states that musical expressiveness is the quality of music to trigger emotions in the listener. That theory faces a circularity problem. It affirms that musical expressiveness depends on the listener's response given that the response itself is supposed to depend upon the expressed emotion (in the explanandum). The multi-space theory avoids, to a certain extent the circularity of the arousal accounts. It suggests that listener's response depends upon the precise location of the musical passage in the assumed multi-space which can fail to be adequate. These overall advantages of Green's theory of expressiveness will help us to explain, in what follows, the epistemic potential of music.

\section{Adequacy conditions of musical expressive ascriptions}

Next, I want to address the issue of adequacy conditions of musical expression. But first, let me draw your attention to the notion of fictional

12 I am grateful to my blind reviewer for raising this question.

13 For an outline of the main theories of musical expressiveness see section "Emotions in the Music" of (Kania 2017). 
truth in literature. There are things true in a literary fiction although, of course, they are not actually true. For instance, "Anna Karenina was driven to suicide by her failed affair" is true in the famous novel by Tolstoy. The debate about fictional truth is mostly limited to literature. However it is useful for our purposes to try to find an analogue in the domain of music. Despite the obvious differences, I claim that there is an analogy between fictional truth and musical expression. This is roughly how it goes:

When a novel $\mathrm{x}$ asserts that $\mathrm{y}$ (and does not deny it), $\mathrm{y}$ is true in $\mathrm{x}$, where $\mathrm{y}$ is a fictional event or state of affairs.

is analogous to

When a musical sequence $\mathrm{x}$ stands within certain parameters in the multi space-time, it is expressive of any state with the same parameters in the multi space-time.

One may think, and rightly so, that the term "truth" is unfortunate when it comes to musical expression. In many cases, $x$ can be expressive of $p, q, y$, or $z$ depending on the associations of the listener. Nevertheless, on my view, all these ascriptions can be adequate to $x$ if they are congruent with $x$. "Being adequate to $x$ ", according to the multi-space theory means occupying the same region in the multi-space that $x$ occupies. So, the listener can adequately associate $x$ with any possible state that occupies the same region in the three-space that $\mathrm{x}$ occupies. Adequacy is the right term here and, of course, it differs from truth. Yet, in some cases, the musical context enables us to choose the most plausible referent of the expression.

Imagine again a musical sequence developing in the multi space-time from point $A$ to point $D$ activating the same regions: $a, b, c$ and $d$ in a listener's mind. I claim that in case of adequate matching, the listener can literary perceive the expressed phenomenal properties. Green is actually skeptical about such possibility:

Another source of resistance to the thesis that some emotions are perceptible might focus on their qualitative dimension. We've acknowledged that many emotions, including the basic ones, often characteristically have a qualitative feel: there is a certain way that rage feels to the person undergoing it; likewise for 
disgust, and perhaps also for happiness and sadness. Furthermore, how these emotions feel is not something that a third party can perceive with her senses: it is far from clear how I might go about observing the qualitative character of your emotion. (Green 2007, 91)

It seems to me that, given the explanatory potential of Green's own multi-space model, such skepticism is unjustified. Music is not only capable of showing how certain states feel but it can do so by making the qualitative characteristics of such states perceptible to the audience. I want to argue that the strength and the originality of Green's theory comes vastly from the fact that it accounts for such a possibility. This gives it a significant advantage over Peter Kivy's contour and convention theory which Green thinks is a necessary complement of his multi-space model. Although Green draws inspiration from Kivy's valuable legacy in philosophy of music, I do not think that he needs to consider the contour and convention theory as an indispensable ground for his own theory.

Let me explain why. Peter Kivy (1980) claims that music expresses emotion by being structurally analogous to human expressive behavior or, where that is not the case, it expresses emotions by convention. The theory fits to a great majority of musical examples. ${ }^{14}$ However, it fails to account for the intuition that music can express contents of inner states independently of purely behavior characteristics, i.e. of purely motor behavior. For example, music can express complex attitudes that have no analogue in human behavior and, at the same time, without previously established conventions.

In her review of Kivy's book The Corded Shell, Anne Hall has detected a similar problem in the contour and convention theory:

Compared to music, physical motion can be quite ambiguous in its expression of emotion. We hear music as feeling when we hear the kinds of processes and events that characterize both music and our feelings: tension, suspension, deception, growth, subsidence, resolution, disintegration, triumph. In order to hear music as feeling we must hear not just its surface characteristics but the

14 For instance, Mussorgski's "Two Polish Jews: Rich and Poor" from Pictures at an Exhibition. 
way it works, its course of events, which is why this seems a more important part of musical experience than the hearing of music simply as analogue of motor behavior. (Hall 1984, 107)

Green's multi-space theory, in contrast, connects musical expressiveness to our inner states. If music is well equipped to recreate the phenomenal path of our mental lives, one might wonder why, at all, considering the analogy with motor behavior? One reason is because music sometimes characterizes events in the external world as opposed to inner states. Such events have contour which the multi-space theory apparently cannot account for. How would Green face the challenge? It is plausible to assume that music "speaks" of external events by sonically recreating our sense impressions of such events in the multi-space. Hence the multi-space theorist can assume that when a musical sequence occupies the same region(s) that our sense-impressions of an external event occupy, it expresses that event. For instance, sunsets feel mild, pleasant and static to us. So, musically, we can represent a sunset by producing a sound sequence that is mild, pleasant and static in a sunset-ish way. ${ }^{15}$ As far as the convention part of Kivy's theory is concerned, it was offered to account for the expressive difference of major and minor chord. Again, I think that the multi-space theory provides a better explanation. Instead of saying that a composition in minor chord sounds sad by convention, the theory says that these compositions have characteristics that occupy the same regions as our sad states. If all that is correct, the multi-space theory has the explanatory resources of the contour-and-convention theory and a sufficient generality to stand on its own ground.

\section{Music and knowledge. The listener's perspective}

In this section, I provide an account of musical knowledge and I try to explain further why listening to music is epistemically valuable. According to Peter Kivy (2002, 135-160 and 251-264) music is not about enriching our

15 For recreating typical characteristics of an external event one may need to use a fine-grained scale of nuances. In this case - to make the sunsetish features more salient - the three parameters maybe insufficient.

Organon F 28 (2) 2021: 303-325 
knowledge; it is about pleasure and enjoyment of musical form with its development in time. From a certain, perspective Kivy is justified to claim that. As we suggested in the beginning of this article, it is clear that music is not meant to deliver propositional knowledge, at least not directly. Secondly, non-propositional knowledge is not considered to be proper knowledge by the majority of epistemologists. Epistemologists working in the analytic tradition have distanced themselves from non-propositional knowledge. There are two strategies to do that. The first one is to restrict the epistemological analysis of knowledge to propositional knowledge only. The second one is to claim that non-propositional knowledge is reducible to propositional knowledge. Also, knowledge about the phenomenology of our states has been vastly underestimated by contemporary epistemologists. One reason for that is because it is considered irrelevant to knowledge of the external world as shown by the inverted spectrum thought experiment. ${ }^{16}$

By "non-propositional knowledge" I mean knowledge-how. I have argued in (Bakalova 2019) that non-propositional knowledge is basic and that it is not reducible to propositional knowledge. I have also argued that both kinds of knowledge can be subsumed under a common account of knowledge offered by Ernest Sosa (2007) and John Greco (2010). The two authors claim that knowledge is success from ability, i.e. that it is an apt performance: successful, because competently formed. In this section, I will use the ability-based account of Sosa and Greco to define musical knowledge.

Ernest Sosa (2007, 22-44) clarifies the above definition of knowledge in the following way. He maintains that each performance has a goal, and can be assessed according to three main criteria: accuracy, adroitness, and aptness (AAA structure). Accuracy is a criterion of successfully achieving the goal, adroitness is a requirement of having the ability for successfully achieving the goal, and finally and crucially, aptness is achieving the goal as a result of applying the ability. The crucial epistemic relation of "aptness" is a causal relation between competence and reaching the goal, where competence is a cause and reaching the goal is an effect. To clarify the notion of aptness, Sosa draws an analogy between a cognizer and an archer. When an archer hits the target as a result of her skill her shot is apt.

16 For a discussion of this topic, see (Chalmers 2004). 
Likewise, when a cognizer reaches cognitive success more generally as a result of her competence, her success is apt and therefore it amounts to knowledge. Even when it comes to propositional knowledge, the epistemic normativity is a kind of performance normativity: beliefs fill in the slot of performances $;^{17}$ truth fills in the slot of success.

The target of our analysis is phenomenal knowledge obtained by listening to music. I take phenomenal knowledge to be a kind of knowledge-how: knowledge how certain mental states feel. It also entails a procedural and more straightforwardly performative kind of knowledge-how where adroitness is salient: having good orientation in the multi-space and eventually being able to use that orientation in practice.

Let me clarify the main components of my analysis which correspond to the structural components of Sosa's account: performance, success, and justifying ability. Our journey starts from attentive listening to expressive music. The first stop is listener's phenomenal grasp of musical expression. The grasp is presumably based on one's sensitivity guided by cross modal congruence. It corresponds to Sosa's performance. Secondly, I take the ability responsible for that grasp to be perceptual ability. In concrete, it is the ability of hearing a musical sequence as a kind of state. Hearing something as something else is a perceptual recognitional ability. I can recognize Emma by the sound of her hills in the corridor. One way to do so is by detecting the phenomenal character of the way she walks. Likewise, musical recognitional ability reliably brings to mind matching or adequate sensations (in the sense described in the previous section). Such recognition can happen with or without emotional contagion.

Let us move to the success component. Exercise of ability in question can amount to hearing or seeming to hear a musical fragment as expression of certain state. In successful cases, one hears musical expressions adequately. If the listener only seems to hear an expression without actually hearing it, it would not count as success. In such cases, the listener might be biased by her own subjective attitudes or distracted by her momentary moods or she may have lost the ability.

17 For criticism, see Engel (2013) 
In sum, when a listener is able to follow perceptually the phenomenal character of a musical expression and she does so as a result of attentively exercising her ability, she gains musical knowledge. We are now ready to propose our definition of musical knowledge which combines Green's multispace model of musical expressiveness with Sosa-style virtue epistemology: ${ }^{18}$

$M K$ : A listener knows that a piece of music is expressive of certain state $x$ iff the listener's grasp of $x$ is adequate because adroitly placed on the multi-space occupied by $x$.

I think that this definition of musical knowledge is not prima facie controversial. What is more controversial perhaps is the value of musical knowledge. So, at the end of this article, I would like to say few words about the value of musical knowledge as defined here - knowledge that is exclusively a product of listening to music. I think that such knowledge enables us to go deeper into how we experience our lives and how other people do so. It enhances our orientation in the multi-space of sensual information, and enables us not only to imagine but also to have vivid awareness of certain states when needed. For instance, the capability of evoking vivid awareness helps us to understand and empathize with others when they are in need. It matters also in situations where we have to take rational decisions based on our estimation of emotional consequences. Together with that, not only one's emotional intelligence grows, but one's expressive intelligence grows too. In sum, awareness of the qualitative side of our experiences could impact our values and decisions that we make personally and as a society: our capability of practical wisdom, interacting with each other, giving pleasure to each other, enhancing and raising the quality of our lives. Finally, I hope that this article makes a modest contribution towards appreciating the epistemic value of music and also- that it encourages the analysis of non-propositional knowledge about which we know so little.

18 For instance the basic principles outlined in (Sosa 2007). 


\section{References}

Bakalova, Marina. 2019. "Why Practical Knowledge is Basic?" In Traditional Learning Theories, Process Philosophy and AI, edited by Katie Anderson, and Vesselin Petrov, 51-63. Louvain-la-Neuve: Chromatika.

Block, Ned. 2003. "Mental Paint." In Reflections and Replies: Essays on the Philosophy of Tyler Burge, edited by Martin Hahn, and Bjørn Ramberg, 165-200. Cambridge, Mass.: MIT Press.

Campbell, Mary. 1989. "Dan Hartman Manages to turn a Career", Mohave Daily Miner 6, Mar. 7: 22.

Davies, Stephen. 2011. Musical Understandings and Other Essays on the Philosophy of Music. Oxford: Oxford University Press. https://doi.org/10.1093/acprof:oso/9780199608775.001.0001

Engel, Pascal. 2013. "Sosa on the Normativity of Belief." Philosophical Studies 166 (3): 617-24. https://doi.org/10.1007/s11098-013-0200-0

Green, Mitchell. 2007. Self-Expression. Oxford: Oxford University Press. https://doi.org/10.1093/acprof:oso/9780199283781.001.0001

Hall, Anne C. 1984. Review of The Corded Shell: Reflections on Musical Expression, by Peter Kivy. Music Theory Spectrum 6: 103-10. https://doi.org/10.2307/745807

Chalmers, David. 2004. "The Representational Character of Experience." In The Future for Philosophy, edited by Brian Leiter, 153-82. Oxford: Oxford University Press.

Damasio, Antonio. 1994. Descartes' Error: Emotion, Reason, and the Human Brain. New York: Grosset/Putnam Book.

Fodor, Jerry. 2008. Lot 2: The Language of Thought Revisited. Oxford: Oxford University Press. https://doi.org/10.1093/acprof:oso/9780199548774.001.0001

Greco, John. 2010. Achieving knowledge: A virtue-theoretic account of epistemic normativity. Cambridge: Cambridge University Press. https://doi.org/10.1017/CBO9780511844645

Kamberi, Ferdi, and Besim Gollopeni. 2015. "The Phenomenon of Sexual Harassment at the Workplace in Republic of Kosovo." International Review of Social Sciences 3 (12): 580-92.

Kania, Andrew. 2017. "The Philosophy of Music." The Stanford Encyclopedia of Philosophy (Fall 2017 Edition), edited by Edward N. Zalta. Last updated July 11, 2017. https://plato.stanford.edu/archives/fall2017/entries/music/

Kivy, Peter. 1989. Sound Sentiment: An Essay on the Musical Emotions, Including the Complete Text of "The Corded Shell". Philadelphia: Temple University Press.

Kivy, Peter. 2002. Introduction to a Philosophy of Music. Oxford: Clarendon Press. 
Marks, Lawrence. 1978. The Unity of the Senses: Interrelations Among the Modalities. New York: Academic Press.

Marks, Lawrence. 1982. "Bright Sneezes and Dark Coughs, Loud Sunlight and Soft Moonlight." Journal of Experimental Psychology: Human Perception and Performance 8: 177-93. https://psycnet.apa.org/doi/10.1037/0096-1523.8.2.177

Marks, Lawrence. 1987. "On Cross-Modal Similarity: Auditory-visual Interactions In Speeded Discrimination." Journal of Experimental Psychology: Human Perception and Performance 13: 384-94.

https://psycnet.apa.org/doi/10.1037/0096-1523.13.3.384

Marks, Lawrence. 1995. "Intermodal Similarity and Cross-modality Matching: Coding perceptual dimensions." In Geometric Representations of Perceptual Phenomena, edited by R. Duncan Luce, Michael D'Zmura, Donald Hoffman, Geoffrey J. Iverson, and A. Kimball Romney, 207-33. Hillsdale, NJ: Erlbaum. https://doi.org/10.4324/9780203773949

Noordhof, Paul. 2018. "Imaginative Content." In Perceptual Imagination and Perceptual Memory, edited by Fiona Macpherson, and Fabian Dorsch, 96-133. Oxford: Oxford University Press.

https://doi.org/10.1093/oso/9780198717881.003.0006

Siegel, Susanna. 2016. "The Contents of Perception." The Stanford Encyclopedia of Philosophy (Winter 2016 Edition), edited by Edward N. Zalta. Last updated October 4, 2016. https://plato.stanford.edu/archives/win2016/entries/perception-contents/

Sosa, Ernest. 2007. A Virtue Epistemology: Apt Belief and Reflective Knowledge. Volume One. Oxford: Oxford University Press. https://doi.org/10.1093/acprof:oso/9780199297023.001.0001

Wilson, Robert A., and Frank C. Keil, eds. 1999. The MIT Encyclopedia of the Cognitive Sciences. Cambridge Mass. and London, England: MIT Press.

Zvolenszky, Zsófia. 2016. "Fictional Characters, Mythical Objects and the Phenomenon of Inadvertent Creation." Res Philosophica 2 (93): 311-33.

https://doi.org/10.11612/resphil.2016.93.2.2 